\title{
Letters
}

\section{Screening for depression in primary care}

Scientific and statistical errors should have been picked up in peer review

EDITOR-The paper by Henkel et al contains several scientific and statistical errors, which should have been identified and eliminated by the $B M T$ 's peer review process before publication. ${ }^{1}$ The study is described as a cohort study but is a cross sectional study.

The general health questionnaire is inappropriate as a screening test for depression and should not be compared with a gold standard test that is specific for depression. It is a screening test for the "common mental disorders" that often occur in primary care, ${ }^{2}$ with a good sensitivity but poor specificity for depression.

Henkel et al choose sensitivity and negative predictive value as measures of how well their tests perform. Sensitivity should be paired with specificity. Sensitivity and negative predictive value are not independent.

They do not make clear their primary hypothesis or explain what questions they are seeking to examine in their analysis. With so many different measures that they could compare, a plan of analysis is essential. They could, for example, start with an omnibus test for sensitivity, such as Cochran's Q. ${ }^{3}$

Henkel et al use one sided statistical tests but should have used two sided tests. Exact $\mathrm{P}$ values or confidence intervals should have been given. Fleiss gives the procedure for confidence intervals in matched pairs. ${ }^{3}$

They have carried out multiple statistical tests without making a correction. To maintain the overall probability of obtaining a type I error at 0.05 , a Bonferroni or other correction is usually made to the significance level of the test.

Henkel et al have not allowed for differences in the sensitivity, etc, between general practitioners. They should have measured the variation between general practitioners and the overall analysis should be adjusted for clustering.

The World Health Organization recommends screening patients in general practitioners' surgeries, but a systematic review of

\section{bmj.com}

Letters appearing here are an edited selection of rapid responses originally posted on bmi.com

We ask for all letters to the editor to be submitted as rapid responses via bmj.com

For advice see: bmj.com/rapidresponses the use of routinely administered questionnaires for depression and anxiety showed that screening tests do not improve diagnosis rates or outcomes in primary care settings. ${ }^{4}$

William P Plummer consultant psychiatrist

East Kent Community NHS Trust, St Martin's Hospital, Canterbury, Kent CT1 1AZ mail@plummer.u-net.com

Competing interests: None declared.

1 Henkel V, Mergl R, Kohnen R, Maier W, Moller HJ, Heger U. Identifying depression in primary care: a comparison of U. Identifying depression in primary care: a comparison of
different methods in a prospective cohort study. BMJ

2003;326:200-1. (25 January.)

Goldberg D, Huxley, P. Common mental disorders: a bio-social model. London: Routledge, 1992

Fleiss JL. Statistical methods for rates and proportions. 2nd ed. Chichester: Wiley, 198

Gilbody SM, House AO, Sheldon TA. Routinely administered questionnaires for depression and anxiety: systemtic review. BMJ 2001;322:406-9.

\section{Chosen tool makes little sense}

EDITOR-When testing screening questionnaires the best possible available instrument should be used as the reference standard. In their comparison of routine screening by brief questionnaire with a clinical assessment of depression made by a family doctor, Henkel et al chose a self report survey questionnaire, the composite international diagnostic interview (CIDI), as their reference standard for diagnosing depression in primary care. ${ }^{1}$

However, they overlooked a comparison in the community of their reference instrument with the World Health Organization's semi-structured clinical interview. This shows that the sensitivity of the composite international diagnostic interview for clinician assessed current depression was only $0.5(95 \%$ confidence interval 0.12 to 0.88 ) and diagnostic agreement was also poor. The questionnaire was designed for use in large epidemiological surveys, where the many thousands of assessments required would render clinical interviewing impractical. ${ }^{3}$ But in the study by Henkel et al only 431 reference assessments were required, and psychologists were available to conduct these by telephone.

The authors cited work from which they could easily have chosen another widely used structured clinical evaluation (SCID, structured clinical interview for DSM-III-R) as the reference standard for diagnosing depression. ${ }^{4}$ This questionnaire was used to evaluate another short screening questionnaire (PRIME-MD), designed for use in primary care. ${ }^{5}$ Their chosen design, testing the sensitivity of a family doctor's clinical assessment by comparing it with a self report tool intended for survey prevalence estimation, makes little clinical or scientific sense.

Traolach S Brugha professor of psychiatry

Section of Social and Epidemiological Psychiatry, Department of Psychiatry, University of Leicester, Department of Psych Leicester LE5
tsb@le.ac.uk

Competing interests: None declared.

1 Henkel V, Mergl R, Kohnen R, Maier W, Moller HJ, Heger U. Identifying depression in primary care: a comparison of different methods in a prospective cohort study. $B M$ 2003:326:200-1. (25 January)

2 Brugha TS, Jenkins R, Taub NA, Meltzer H, Bebbington P A general population comparison of the composite international diagnostic interview (CIDI) and the schedules for clinical assessment in neuropsychiatry (SCAN). Psychol Med 2001;31:1001-13.

Robins LN, Wing J, Wittchen HU, Helzer JE, Babor TF Burke J, et al. The composite international diagnostic interview. An epidemiologic instrument suitable for use i conjunction with different diagnostic systems and in different cultures. Arch Gen Psychiatry 1988;45:1069-77.

4 Spitzer RL, Williams JB, Gibbon M, First MB. The structured clinical interview for DSM-III-R (SCID). I. History, rationale, and description. Arch Gen Psychiatry 1992;49:624-9.

5 Spitzer RL, Kroenke K, Williams JB. Validation and utility of a self-report version of PRIME-MD: the PHQ primary care study. Primary care evaluation of mental disorders. Patient health questionnaire. JAMA 1999;282:1737-44.

\section{Study analysis and conclusions are} flawed

EDITOR-Henkel et al recommend using the WHO-5 depression self rating instrument as a screening tool in primary care, saying that it is a superior method to unaided clinical diagnosis. ${ }^{1}$ Unfortunately, their analysis and conclusions are flawed.

The table ( $\mathrm{p}$ 983) summarises the most clinically meaningful way of presenting results of diagnostic or screening tests-as positive likelihood ratios (sensitivity/(1specificity)) and the consequent post-test probability of detecting depression in primary care. The WHO-5 self-rated instrument is no different from unaided clinical diagnosis. The instrument that performs the best is the brief patient held questionnaire (B-PHQ), but even this provides a post-test probability of depression of just over $50 \%$.

The prior probability of depression in this cohort is $17 \%$. The prior probability of depression is highly dependent on the age and sex of patients consulting, as well as other important sociodemographic variables. $^{2}$ Uncritical application of an unselected prior of $17 \%$ is misleading and does not reflect the clinical reality of primary care practice.

Even if these self rating instruments did perform well as effective screening tools (they clearly do not), Henkel et al do not 
Test accuracy of screening questionnaires and family doctors' unaided clinical diagnosis (adopted from Henkel et al')

\begin{tabular}{lcccc} 
& Sensitivity (\%) & Specificity (\%) & $\begin{array}{c}\text { Positive likelihood } \\
\text { ratio (95\% CI) }\end{array}$ & $\begin{array}{c}\text { Post-test probability } \\
\text { of depression (\%) } \\
\text { (95\% Cl) }\end{array}$ \\
\hline WH0-5 wellbeing index & 93 & 64 & $2.6(2.2$ to 3.0) & 34.6 (31.2 to 45.4) \\
\hline General health questionnaire-12 & 85 & 62 & $2.2(1.9$ to 2.6) & 31.4 (27.9 to 35.0) \\
\hline Brief patient health questionnaire & 78 & 85 & $5.2(3.9$ to 6.8) & 51.5 (44.6 to 58.3) \\
\hline Unaided clinical diagnosis & 65 & 74 & $2.5(2.0$ to 3.2) & 34.1 (28.9 to 37.9) \\
\hline
\end{tabular}

mention a recent systematic review published in the $B M J$ which shows that using self rating questionnaires for detection and treatment of anxiety and depression does not increase the recognition of these disorders and has no effect on patients' outcome. ${ }^{3}$ General practitioners are in fact more likely to initiate treatment for patients whom they themselves have diagnosed as depressed.

Contrary to Henkel et al's conclusion, their study does not provide any evidence that use of these self rating instruments for screening of depression in primary care is an effective or cost effective strategy.

Tom Fahey professor of primary care medicine t.p.fahey@dundee.ac.uk

Frank Sullivan professor of research and development in primary care

Tayside Centre for General Practice, University of Dundee, Dundee DD2 4AD

Steve MacGillivray research fellow

Department of Epidemiology and Public Health, University of Dundee, Ninewells Hospital and Medical School, Dundee DD1 9SY

Competing interests: None declared.

1 Henkel V, Mergl R, Kohnen R, Maier W, Möller H-J, Heger U. Identifying depression in primary care: a comparison of different methods in a prospective cohort study $B M J$ 2003;326:200-1. (25 January)

2 Okkes IM, Oskam SK, Lamberts H. The probability of specific diagnoses for patients presenting with common symptoms to Dutch family physicians. I Fam Pract 2002;51:31-6.

3 Gilbody S, Touse A, Sheldon T. Routinely administered questionnaires for depression and anxiety: systematic review. BMJ 2001;332:406-9.

4 Dowrick C. Does testing for depression influence diagnosi or management by general practitioners? Fam Pract 1995;12:461-5

\section{Authors' reply}

EDITOR-Several responses to our report have referred to the issue of effectiveness of screening for depression. This is a key issue but was not the main focus of our study. Increased recognition of depression does not necessarily translate into improved outcome of depression. Screening can be regarded as only one part of a bundle of measures to reduce diagnostic and thera-

Sensitivity and specificity of three screening instruments for depression in primary care

\begin{tabular}{|c|c|c|c|c|c|}
\hline & \multicolumn{3}{|c|}{ Screening questionnaire } & \multirow[b]{2}{*}{$\begin{array}{l}\text { Unaided } \\
\text { clinical } \\
\text { diagnosis }\end{array}$} & \multirow[b]{2}{*}{ Comparison } \\
\hline & $\begin{array}{l}\text { WHO-5 } \\
(\leq 13)\end{array}$ & $\begin{array}{c}\text { GHQ-12 } \\
(\geq 2)\end{array}$ & $\begin{array}{c}\text { B-PHQ } \\
(\geq 2 \text {, including } \\
\text { 1a or } 1 \mathrm{~b})\end{array}$ & & \\
\hline Sensitivity (\%) & 93.06 & 84.72 & 77.78 & 65.28 & $\begin{array}{l}\text { WH0-5> B-PHQ, unaided } \\
\text { clinical diagnosis }(P \leq 0.001)\end{array}$ \\
\hline Specificity (\%) & 64.35 & 62.12 & 85.24 & 74.09 & $\begin{array}{c}\mathrm{B}-\mathrm{PHQ}>\text { unaided clinical } \\
\text { diagnosis }>\text { WHO-5, GHQ-12 } \\
(\mathrm{P} \leq 0.001)\end{array}$ \\
\hline
\end{tabular}

These results are tentative until confirmed by subsequent studies.

WH0-5=WH0-5 wellbeing index, 5 items; GHQ-12=general health questionnaire, 12 items; B-PHQ=depression module of the brief patient health questionnaire, 9 items.

peutic deficits-for example, doctors in primary care should be trained how to interpret screening results and must have resources available for effective intervention.

Our comparative study was exploratory. Hypotheses were not generated; neither a hierarchical plan for statistical analysis for testing confirmatory hypotheses nor Bonferroni correction was conducted. If two sided tests and Bonferroni correction $(\mathrm{P} \leq .002)$ are applied, the results do not change our conclusions (table below).

The use of the general health questionnaire in our study has been criticised. This had been selected because it was developed to detect non-psychotic psychopathology in primary care and performs best in identifying symptoms of depression. ${ }^{1}$

Our reference standard (CIDI) is a standardised, fully structured diagnostic interview and was selected for its reliability and validity. ${ }^{2}$ The structured clinical interview for DSM-III-R would have been an option. ${ }^{3}$ It would be interesting to replicate the study using this reference standard.

We tested the comparative validity of screening instruments for depression in the context of an ongoing prospective cohort study. In this study, depressed patients in primary care-as screened by family doctorsare included in a clinical study. Its objective is to compare outcomes in primary care patients receiving different treatment strategies for depression. One year later, a follow up examination for all patients took place (this information was omitted when the original manuscript was abbreviated).

The most relevant psychometric variable of screening questionnaires is sensitivity. Emphasising specificity and the use of likelihood ratios make sense more for diagnostic than for pure screening purposes. Our study confirmed previous results, showing that general practitioners tend to outperform various screening questionnaires in terms of specificity while tending to miss many cases. ${ }^{4}$ Therefore, the best working compromise seems to be the final diagnosis of the primary care doctor when he or she takes into account the result of a highly sensitive screening tool. Using WHO-5 in routine clinical practice would increase general practitioners' alertness about depression.

Verena Henkel psychiatrist

verena.henkel@psy.med.uni-muenchen.de

Roland Mergl psychologist

Ulrich Hegerl professor

Department of Psychiatry,

Ludwig-Maximilians-University Munich,

Nußbaumstrasse 7, D-80336 Munich, Germany

Competing interests: None declared.

1 Newman SC, Bland RC, Orn H. A comparison of method of scoring the general health questionnaire. Compr Psychiatry 1988;29:402-8.

2 Andrews G, Peters L. The psychometric properties of the composite international diagnostic interview. Soc Psychiatr Psychiatr Epidemiol 1998;33:80-8.

3 First MB, Spitzer RL, Williams JBW, Gibbon M. Structured clinical interview for DSM-IV (SCID). Washington, DC: American Psychiatric Association, 1995.

4 Wilkinson MJB, Barczak P. Psychiatric screening in general practice: comparison of the general health questionnaire and the hospital anxiety depression scale.J R Coll Gen Pract 1988;38:311-3.

\section{Cardiovascular mortality after radiotherapy for breast cancer}

Study showed only estimates of use of adjuvant radiotherapy

EDITOR-The headline on the BMJ's front cover "Cardiovascular mortality after radiotherapy for breast cancer" would lead the reader to suppose that the study described the relation between adjuvant irradiation for breast cancer and cardiac mortality. ${ }^{1}$ The actual report of a cohort of nearly 90000 women reported from the Swedish cancer registry with data on laterality of breast cancer and cardiac mortality presents only estimates of the use of adjuvant radiotherapy $(30 \%)$ from regional Swedish registries in the 1970 s and 1980 s.

Darby et al are rightly modest in their claims about the increased mortality ratio (left $v$ right) of 1.10 because of the wide confidence intervals for the observed ratio. This study, like the meta-analyses of trials of postoperative locoregional irradiation for early breast cancer, treats radiotherapy as a uniform intervention. This takes no account of the volume of heart irradiated, preexisting cardiac morbidity, dose and fractionation, or the use of adjuvant chemotherapy that contains potentially cardiotoxic anthracycline.

The combined analysis of the premenopausal and postmenopausal trials of the Danish Breast Cooperative Group has shown that electron based techniques for minimising transmitted dose to the heart are effective in avoiding radiation induced cardiac toxicity. ${ }^{2}$ However, the techniques adopted in these trials are labour intensive and not widely practised. The recent introduction of intensity modulated radiotherapy allows the shaping of the irradiated volume to minimise cardiac irradiation. However, as yet there are no long term follow up data confirming the reduction in 
radiation induced mortality. This technique is likely to become more widely adopted. What are needed are prospective cohort studies linking cancer registry data, detailed description of the parameters of radiotherapy, irradiated cardiac volume, use of anthracycline based chemotherapy, cancer control and cardiovascular morbidity and mortality. Only then will the specific cardiac risks of adjuvant irradiation be accurately assessed.

Ian H Kunkler consultant in clinical oncology Western General Hospital, Edinburgh EH4 2XU i.kunkler@ed.ac.uk

Competing interests: None declared.

1 Darby S, McGale P, Peto R, Granath F, Hall P, Akbom A. Mortality from cardiovascular disease more than 10 years after radiotherapy for breast cancer: nationwide cohort
study of 90000 Swedish women. BMJ 2003.326:256-7. (1
February.)

2 Hojris I, Overgaard M, Christensen JJ, Overgaard J. Morbidity and mortality of ischaemic heart disease in 3083 Morbidity and mortality of ischaemic heart disease in 3083 high-risk breast cancer patients given adjuvant systemic therapy treatment with or without postmastectomy irradiation: analysis of DBCG
trials. Lancet 1999;354:1425-30.

\section{Article showed nothing new}

EDIToR-The Early Breast Cancer Trialists' Collaborative Group reported long term follow-up of patients treated by radiotherapy for breast cancer and showed an increased mortality rate from cardiovascular events. ${ }^{1}$ This is widely known and accepted in oncology. However, it is related to what would now be considered as poor radiotherapy techniques and poor fractionation schedules.

More recent reports have shown not only the established two thirds reduction in local recurrence when radiotherapy is used after mastectomy, but also an overall survival benefit of around $9 \% .^{2-4}$ In addition, Overgaard has shown no excess cardiac deaths in patients followed up for over 10 years. ${ }^{4}$ As a result, many patients who have had a mastectomy will now also receive postoperative radiotherapy.

Current radiotherapy practice demands high precision. Patients are positioned with their arms raised above the head on the couch, which alters the position of the soft tissues to be irradiated and reduces or excludes the heart from the radiation field. Additional shielding of the heart can be used and in centres that have provision of conformal radiotherapy, the radiation fields can be shaped to avoid the heart.

I therefore find it surprising that a study from Sweden was recently published in this journal, which does not provide any new information and refers to outmoded radiotherapy. ${ }^{5}$ I also find it surprising that the substantial hazard in cardiovascular mortality reported is calculated from unpublished data, implying that around 30\% of women with early breast cancer received radiotherapy.

Adrian N Harnett consultant clinical oncologist Norfolk and Norwich University Hospital, Colney Centre, Norwich, Norfolk NR4 7UY adrian.harnett@nnuh.nhs.uk

Competing interests: None declared. 1 Early Breast Cancer Trialists' Collaborative Group. Favourable and unfavourable effects on long-term survival
of radiotherapy for early breast cancer: an overview of the randomised trials. Lancet 2000;355:1757-0.

2 Overgaard M, Hansen PS, Overgaard J, Rose C, Andersson Overgaard M, Hansen PS, Overgaard J, Rose C, Andersson $\mathrm{M}$, Bach F, et al. Postoperative radiotherapy in high-ris premenopausal women with breast cancer who receive adjuvant chemotherapy. N Engl J Med 1997;337:949-55. 3 Ragaz J, Jackson SM, Le N, Plenderleith IH, Spinelli JJ Basco VE, et al. Adjuvant radiotherapy and chemotherap in node-positive premenopausal wo

Cancer. NEngl J Med 1997;337:956-62. Overgaard M, Jensen M-J, Overgaard J, Hansen PS, Rose C, Andersson M, et al. Postoperative radiotherapy in highrisk postmenopausal breast-cancer patients given adjuvan tamoxifen: Danish Breast Cancer Cooperative Gro DBCG 82c randomised trial. Lancet 1999,353:1641-8. Mor S, AcGale P, Peto R, Granath F, Hall P, Akbom A. Mortality from cardiovascular disease more than 10 year after radiotherapy for breast cancer: nationwide cohor (1 February.)

\section{Monitoring marketing of infant formula feeds}

WHO's global strategy is tool to protect breast feeding and child health

EDITOR-Waterson and Tumwine assert that governments should accept promotion and protection of breast feeding as critical for improving child health. ${ }^{1}$ In May 2002 the World Health Assembly produced its strategy for infant and young child feeding. ${ }^{2}$ The World Health Organization's international code of marketing of breast milk substitutes and subsequent relevant assembly resolutions are integral to this strategy, which is intended as a model for all governments to adapt and adopt as national policy.

In the United Kingdom there is no indication that the government is considering this strategy or intends to commit to a comprehensive national policy, including the implied collection and evaluation of information. ${ }^{2}$ Currently only some provisions of the WHO code and World Health Assembly resolutions are enacted in UK legislation; no formal monitoring has been undertaken; legal mechanisms for enforcement have proved cumbersome. Since the United Kingdom performs poorly in terms of breastfeeding rates in comparison with other European countries there is no room for complacency (R Saadev, Department of Health conference on barriers to breast feeding, London, 2002).

If the United Kingdom were to commit to a national policy on feeding infants and young children it would help protect child health in the United Kingdom. In addition, if full collaboration of all concerned government agencies were implemented effectively, aid to low income countries could include capacity building so that countries such as Togo and Burkina Faso would have the means to monitor the protection of their children's health. Currently monitoring is all too often left to small non-governmental groups operating on shoestring budgets. Let us take heed of the warning from west Africa and act now in the United Kingdom to contribute nationally to global child health. ${ }^{4}$

Magda Sachs breastfeeding supporter

Breastfeeding Network, PO Box 21116, Paisley PA2 8YB

magda@sachsdavis.clara.net
Competing interests: MS is an adviser to Baby Milk Action, the UK member of the International Baby Feeding Action Network (IBFAN)

1 Waterston T, Tumwine J. Monitoring the marketing of infant formula feeds. BMJ 2003;326:1 13-4. (18 January.) World Health Organization. Infant and young child nutrition: global strategy on infant and young child feeding. Geneva: WHO, 2002.

WHA55/ea5515.p

World Health Organization. International code of marketing of breast-milk substitutes. Geneva: WHO, 1981.

4 Aguayo VM, Ross JS, Kanon S, Ouedraogo AN Monitoring compliance with the International Code of Marketing of Breastmilk Substitutes in west Africa multisite cross sectional survey in Togo and Burkina Faso. BMJ 2003;326:113-4. (18 January.)

\section{Manufacturers encourage transparent} and official monitoring of WHO code

EDITOR-Waterston and Tumwine's editorial and the study it describes are an example of why the International Association of Infant Food Manufacturers supports a better way to monitor and enforce the code in many countries. ${ }^{2}$ Our member companies are committed to the health and wellbeing of infants and young children. We support the aims and principles of the WHO code. For the code to succeed, however, national governments must oversee monitoring and enforcement in keeping with their own legislative and regulatory framework. The code itself recommends this, and indeed it is key to its success.

The reported study was led by a representative of the International Baby Feeding Action Network, which has devised its own system of monitoring. Under the WHO code, monitoring groups are required to inform companies of alleged noncompliance immediately so that they can respond and take corrective actions, if necessary. Yet in the three years since this monitoring took place, none of the researchers contacted the companies mentioned.

Data collection for the study was based on inaccurate interpretations of the WHO code. Most of the alleged violations refer to products that are complementary foods (such as baby cereals or fruit juices) and not breastmilk substitutes. The code explicitly excludes complementary foods from the marketing restrictions. Accusations came to light only in this article.

We are interested in cooperation and partnership with WHO, other institutions dedicated to the welfare of children, non-governmental organisations, and our member companies. To protect the health and promote nutrition of infants and young children, governments need to be encouraged to enforce the WHO code; monitoring must be based on research methods that fulfil basic reliability criteria, be transparent, and be carried out according to national legislation and standards. Only when we are focused on this shared goal will the code succeed.

Andrée Bronner secretary general

International Association of Infant Food Manufacturers, 194 rue de Rivoli, F75001 Paris, France

andree.bronner@wanadoo.fr

Competing interests: None declared. 
1 Waterston T, Tumwine J. Monitoring the marketing of infant formula feeds. BMJ 2003;326:1 13-4. (18 January.) Aguayo VM, Ross JS, Kanon S, Ouedrogo AN. 2 Aguayo VM, Ross JS, Kanon S, Ouedraogo AN Monitoring compliance with the International Code of Marketing of Breastmilk Substitutes in west Africa: BMJ 2003;326:113-4. (18 January.)

\section{Australian Medical Association accepts generic prescribing}

EDITOR-With reference to the news item by Burton, ${ }^{1}$ the Australian Medical Association has no objection to the prescribing of cheaper equivalent generic drugs, provided that they are indeed equivalent in content and mode of delivery and that patients are not likely to have any adverse consequences. Patients should also fully understand and agree to any switch of drug.

As clinicians we are aware that many patients identify their drugs by colour, size, and shape rather than chemical name. Patients could possibly be given six different generic drugs over six months, depending on which supplier their pharmacist uses.

Our chief concerns centre on patients who are elderly, are illiterate, are intellectually disabled, have visual difficulties, and for whom a change of their usual drug might result in confusion or double dosing-for example, continuing to take the usual drug as well as the new one prescribed in hospital.

The decision must be left to a patient's general practitioner, who is best placed to assess the medical context.

Kerryn Phelps president

Australian Medical Association, PO Box E115, Kingston, ACT 2604, Australia

president@ama.com.au

Competing interests: None declared.

1 Burton B. Changing prescription software to favour generics could save Australia $\$ 40 \mathrm{~m}$ a year. $B M J$ 2003;326:184. (25 January.)

\section{New edicts for letters}

\section{Restrictions should not be imposed on} post-publication peer review

EDITOR-I often read the short letters in newspapers and journals in preference to the long ones. They are simpler to assimilate, quicker to read, and often amusing too. But I know that the important stuff is generally in the longer letters.

Research published in scientific journals should be open to comment and correction in published correspondence. ${ }^{1}$ The $B M J$ has reduced its word limit for letters from 400 to 300 words (barely more than the length of the abstract of the paper one might be writing about), at the same time as Lancet reduced the time window from eight weeks to two. ${ }^{23}$

What next-a maximum of 800 words for research papers? More people would read them, I'm sure.

There is an effective "statute of limitations" in leading journals, whereby authors of papers are immune to disclosure of methodological weaknesses once some arbitrary (short) period has elapsed. ${ }^{4}$ Such time limits (four weeks at the $B M J$ ) discourage post-publication peer review. Similarly, one often cannot adequately address multiple and complex concerns about a study in a short letter.

Convenience should not take precedence over science. Brevity is not more important than scientific rigour. Editors are hiding behind arbitrary rules to avoid having to decide what is actually important. Such restrictions may be suitable for a magazine but not for a scientific journal.

I applaud the rapid responses on bmj.com. It is shocking that so few journals have followed suit. But, although it remains the case that only those published in the paper version get linked to the original article on PubMed, publication in the paper journal should not be determined by rules.

By all means encourage brevity and rapid submissions, but do not rule out longer or later publication if the circumstances warrant it. In particular, letters that draw attention to methodological flaws should not be time limited.

Douglas G Altman professor of statistics in medicine Cancer Research UK, NHS Centre for Statistics in Medicine, Institute of Health Sciences, Oxford OX3 7LF

doug.altman@cancer.org.uk

Competing interests: None declared.

1 Report of the World Association of Medical Editors Report of the World Association of Medical Editors
(WAME). An agenda for the future. wwwwame.org/ (WAME). An agenda for the future. WW

Davies S. New edicts for letters to the editor. $B M J$ 2003;326:63-4. (11 January.)

Mullan Z. Lancet correspondence: old letters, new rules. Lancet 2003;361:12.

Alitical research: what can journals do? JAMA 2002:287:2765-7.

Post-publication peer review should have its place

EDITOR-The BMJ recently announced a change in its editorial policy concerning correspondence. ${ }^{1}$ In an effort to make this section more readable and interesting, letters are no longer be accepted "for their detailed critique of science."

I think that letters discussing the scientific aspects of original articles have always been relatively infrequent and need more encouragement rather than less. ${ }^{2}$ Despite improvements in the assessment of submitted manuscripts, post-publication peer review remains important (for example, identifying statistical errors ${ }^{4}$ and unconsidered potential biases ${ }^{5}$ ).

The print publication of critical letters is, at present, more likely to correct the medical literature-printed but not electronic comments are linked to article citations in databases such as PubMed.

Furthermore, in this age of evidence based medicine, when all doctors need to be able to appreciate possible weaknesses of studies, we need to see examples. As readers with limited time may focus on printed letters rather than unselected rapid responses, these examples belong in the print edition.

I suggest fostering more readable and interesting scientific critique rather than simply giving up on it. There must be room for the readers' peer review of published articles.

Sean Bydder research fellow

Sir Charles Gairdner Hospital, Perth, WA 6009

Australia

sean.bydder@health.wa.gov.au

Competing interests: None declared.

1 Davies S. New edicts for letters to the editor. $B M$ 2003;326:63-4. (11 January.)

2 Boyton RJ, Arnold PC. An audit of the BMJ's correspondence columns. BMJ 1990;301:1419-20.

Caswell A. Letters to the editor 1991. An audit of the MJA's correspondence columns. Med J Aust 1992;157:63-4.

Bydder S. Invasive brain tumour after radiosurgery. Lance 2001;357:887

5 Bydder S, Joseph DJ, Spry N, Elsaleh H. Breast cancer survival advantage with radiotherapy. Lancet 2000;356:1270.

\section{Brief letters, more letters?}

EDITOR-With reference to Davies's editorial, ${ }^{1}$ I have had more than 20 letters published in the Times and can speak with authority on the issue of brevity.

Success also requires speed, but even my taut missives are pared by the correspondence editors. To pack yet more letters into the printed $B M J$ you must be editors-and edit!

Andrew N Bamji consultant rheumatologist Queen Mary's Hospital, Sidcup DA14 6LT andrewbamji@lineone.net

Competing interests: None declared.

1 Davies S. New edicts for letters to the editor. $B M J$ 2003:326:63-4. (11 January.)

\section{$B M J$ ought to lead its contributors by example}

EDITOR-Davies says that the new guidelines for letters to the $B M J$ will still allow the author's voice to remain audible. ${ }^{1}$ Many years ago, when editor of the British Journal of Industrial Medicine (as it was then), I found that concept a timely brake on my enthusiasm to "correct the English" in accepted papers.

Davies also encouraged letter writers to be both clear and concise. Yet in the very next issue under "This week in the $B M{ }^{\prime}$ " appears this awful specimen:

"The team's appraisal and application of published evidence was crucially informed by a detailed qualitative study of the experiences of students and staff on their course by their own experience as students on other online courses and by informed discussion with other course developers."

Ought not the $B M J$ to lead its contributors by example?

W $\mathbf{R}$ Lee retired emeritus professor

6 Sussex Avenue, Didsbury, Manchester M20 6AQ

Competing interests: None declared.

1 Davies S. New edicts for letters to the editor. $B M J$ 2003;326:63-4. (11 January.) 


\section{$B M J$ may lose correspondents}

EDITOR-Well! Jesus may (or more likely may not) want me for a sunbeam but the $B M J$ most certainly does not want me for a correspondent. ${ }^{1}$

As you are so enchanted with electronics and apparently so disillusioned with the printed word (take note also of the paucity of your book reviews), may I suggest you discontinue the paper version altogether and put me out of my misery.

Robert Richardson medical author

East Pallant Cottage, East Pallant, Chichester,

West Sussex PO19 1TZ

Competing interests: RR has no email address, is not connected to the internet and wouldn't know a website if he was dumped in one. He enjoys reading the printed word and does all his research through this medium.

1 Davies S. New edicts for letters to the editor. $B M J$ 2003;326:63-4. (11 January.)

\section{Autism spectrum disorder is not as certain as implied}

EDITOR-Szatmari's editorial implies more certainty about the existence of an autism spectrum and causes of autism than is warranted. ${ }^{1}$ Debate remains about the validity and usefulness of a broad definition of autism. $^{2}$

Autism and Asperger's syndrome are distinct, and although they share common difficulties in social relatedness and obsessiveness, they can be distinguished in these.

In autism children are withdrawn, whereas in Asperger's syndrome they desire social contact but cannot negotiate rules.

In autism, which, unlike Asperger's syndrome, is associated with mental retardation, obsessiveness commonly entails routine behaviours and physical objects, whereas in Asperger's syndrome it entails idiosyncratic and often highly intellectual interests.

The distinction is comparable to that between schizophrenia and schizoid personality disorder. Like autism and Asperger's syndrome they share common features and genetic loading, but clinically their distinction is crucial. A broad definition risks confusion and overdiagnosis, an increasing problem when worried parents demand diagnostic certainty.

Szatmari's statement that autism is a neuropsychiatric disorder plays into this. Neurological problems have a bearing on autism, but the relation remains obscure and the implied claim that autism results from a primary neurological disorder is based on slim evidence. A genetic link does not necessarily imply neurological damage.

Szatmari acknowledges environmental factors but omits social and emotional factors, although the importance of these for psychological and brain development is well established. Evidence indicating their role in autism comes from studies of Romanian adoptees. ${ }^{3}$
Szatmari believes that research that supports organic causation helps temper parental guilt. In my experience, helping parents understand their unwarranted feelings of blame about their children is more productive than allaying anxiety with premature certainty about causation.

David Simpson consultant child and adolescent psychiatrist

Tavistock Clinic, London NW3 5BA

dsimpson@tavi-port.nhs.uk

Competing interests: None declared

1 Szatmari P. The causes of autism spectrum disorder. $B M$ J 2003;326:173-4. (25 January.)

2 Volkmar FR, Klin A. Diagnostic issues in Asperger's syndrome. In: Klin A, Volkmar FR, Sparrow SS. Asperger's syndrome. New York, London: Guildford Press, 2000:60-3.

3 Rutter M, Anderson-Wood L, Beckett C, Bredenkamp D, Rutter M, Anderson-Wood L, Beckett C, Bredenkamp D, Caste J, Groothues C, et al. Quasi-autistic pattens following severe early global privation.J Child Psychol Psychiatr

\section{Perhaps medicine should now be considered a trade}

EDITOR-After 35 years of dealing with medical students and residents as programme director, the greatest recent deficiency in applying educational theory in practice seems to be personal entitlement and the lack of autodidacticism. ${ }^{1}$ I think that we must start in high schools and colleges (if not earlier) to motivate thinking and cognitive curiosity in order to be successful.

I have used case based learning for 10 years, but I still find among students a general lack of enthusiasm in each student group critique of the tutorials.

Is it too much work for them?

Are we still missing the goals by our antiquated curriculum?

I do not have the answer, and I will continue to apply the systems that appeal to adults. However, I recognise that today's students have emerged from a culture of entitlement, grade inflation, and medical schools that seem more afraid of negative criticism from students than of professors' concerns for the lack of intellectual pursuit.

Perhaps medicine should now be considered a trade and not a profession.

Robert A Knuppel senior vice president for physician development

Saint Peter's University Hospital, New Brunswick, NJ 8054, USA

bobknuppel@yahoo.com

Competing interests: None declared.

1 Kaufman DM. ABC of learning and teaching in medicine. Applying educational theory in practice. $B M J$ 2003;326:213-6. (25 January.)

\section{Personality and performance during a medical degree}

Selecting for extreme personality types is perilous

EDITOR-Pit bull terriers and other hard to accommodate fighting dogs can be bred selectively in a remarkably few generations.
Across the diversity of human individual differences, neither early evolution nor the social norms of civilisation favoured the selection of many people with extreme personality types. The study of Ferguson et al on admissions to medical school found that the dimension of personality labelled "conscientiousness" predicted better performance during pre-registration studies. ${ }^{1}$

A degree of conscientiousness, in the right occupational context, can bring advantages to individual performance in many activities. ${ }^{2}$ However, this does not mean that the medical profession or its patients will necessarily benefit by selecting for ever more and more "conscientious" applicants.

At the extreme, this could mean more and more colleagues who exhibit either an obsessive narrowness in their worldview or a perfectionism that prevents them letting go of work in progress.

Idealising conscientiousness could make for unhappiness in both individuals and the medical profession. In general, higher education and the professions seem to benefit from taking in a rich diversity of people, including some with "ordinary" traits-like those of the public we serve.

There has been at least one natural experiment in this area. Germany's wartime SS "baby farms" in areas such as the Sudetenland selected their prospective parents on three criteria: physical robustness, a pale complexion, and (especially) a sense of duty. Have any of their "dutiful" children since become outstanding doctors?

Woody Caan professor of public health Department of Public and Family Health, Anglia Polytechnic University, Chelmsford CM1 1LL

a.w.caan@apu.ac.uk

Competing interests: WC is on the editorial board of the Journal of Mental Health Promotion.

\section{Ferguson E, James D, O'Hehir F, Sanders A. Pilot study of the roles of personality, references, and personal statements in relation to performance over the five years of a medical degree [with commentary by I C McManus]. BMJ 2003;326:429-32. (1 February.) \\ 2 American Psychological Association. Psychology at work: which traits predict job performance? http:// helping.apa.org/ work/personal.html (accessed 8 Apr 2003).}

\section{Cat is out of the bag}

EDITOR-Now that the elements required in one's personal statement when applying for medical school have been elucidated, will not all canny careers advisers guide students in the wording of their personal statement?

There's one consolation: If all A level students start bragging about how "conscientious" they are, at least the admissions staff know they read the $B M J$.

D R Nethercott senior house officer 108 Newfoundland Road, Heath, Cardiff CF14 3LD

danielnethercott@hotmail.com

Competing interests: None declared.

1 Ferguson E, James D, O'Hehir F, Sanders A. Pilot study of the roles of personality, references, and personal statements in relation to performance over the five years of a medical degree [with commentary by $1 \mathrm{C}$ McManus]. BMJ 2003;326:429-32. (22 February.) 